\title{
Histophysiological Evaluation of the Effect of Alpha-Tocopherol and Dimethyl Diphenyl Bicarboxylate on Arsenic-Induced Hepatotoxicity in Adult Male Albino Rats
}

\author{
Ahmed T. Elshennawy, *Mahmoud A. El-Gharieb and \\ **Mohammad A. Hashem \\ Department of Histology, Faculty of Medicine, El-Minya University, \\ * Department of Physiology, Faculty of Medicine, Tanta University and \\ **Department of Forensic \& Toxicology, Faculty of Medicine, \\ El-Minya University, Egypt
}

\begin{abstract}
Arsenic, a widely studied medicinal and toxicological element, is known to induce oxidative stress and damage to cells. The present study was aimed at to assess the effect of vitamin E (alpha-tocopherol) and/or DDB (dimethyl diphenyl bicarboxylate) with or without the chelator DMSA (Meso 2,3-dimercaptosuccinic acid) on arsenicinduced hepatotoxicity. Fifty four adult male albino rats were divided into nine groups. Group I was the control and received only intraperitoneal injection normal saline 2 times per week for two weeks. Group II was injected with sodium arsenite in normal saline 2 times /week for 2 weeks. Group III was injected with sodium arsenite and received oral DMSA daily for 2 weeks. Group IV was injected with sodium arsenite and received oral vitamin E (alpha -tocopherol) daily for 2 weeks. Group V was injected with sodium arsenite and received oral DDB daily for 2 weeks. Group VI received sodium arsenite, vitamin $E$ and $D D B$ for 2 weeks. Group VII received sodium arsenite, DMSA and vitamin E for 2 weeks. Group VIII received sodium arsenite, DMSA and DDB for 2 weeks. Group IX received sodium arsenite, DMSA, vitamin $E$ and $D D B$ for 2 weeks. Physiological and biochemical parameters were undertaken to measure Alanine Amino-Transferase (ALT), Aspartate AminoTransferase (AST), Malondialdehyde (MDA), reduced Glutathione (GSH) and Glutathione Peroxidase (GPx). Histochemical and histpathological parameters were also undertaken to assess the structural-functional mirror changes. The results of this study showed that vitamin $E$ and $D D B$ were almost similar in their antioxidant hepatoprotective effects with stronger inhibiting action of DDB to lipid peroxidation while the greatest effect was achieved by their combination with a chelating agent like DMSA with restoration of almost the normal hepatic histology.
\end{abstract}

\section{INTRODUCTION}

The metalloid arsenic (As) is an industrial element, medicinal agent, homicidal poison and unfortunately an unintentional self-poison in contaminated drinking water ${ }^{(\mathbf{1 , 2})}$.
Arsenic may cause black foot disease and malignancies of skin, lung, liver and urinary bladder ${ }^{(\mathbf{1 , 3}, \mathbf{4})}$. Arsenite toxicity may be exerted thru the generation of metabolic reactive oxygen species (ROS) or via reactions with intracellular thiols particularly 
vicinal dithiols ${ }^{(5,6,7)}$. The human cells methylate inorganic arsenic to monomethyl-arsonic acid (MMA) and dimethyl arsenic acid (DMA) while reduced glutathione (GSH) stimulates the methylation of arsenic and augments the excretion of DMA ${ }^{(\mathbf{8 , 9 , 1 0 )} \text {. }}$ Glutathione, the most abundant cellular non-protein thiol, exerts many physiological roles such as detoxification reactions, storage and transport of amino acids especially cysteine $^{(11)}$. The tripeptide reduced glutathione (GSH) is an essential antioxidant against many free radicals which may damage membrane proteins and lipids ${ }^{(\mathbf{1 2}, \mathbf{1 3})}$. GSH may form a complex with arsenite, a thiolreacting element, and excreted in bile as GSH complex, so the level of cellular GSH will be decreased ${ }^{(14)}$. Glutathione peroxidase (GPx) plays a critical role in protecting the cell from free radicals damage particularly that related to lipid peroxidation ${ }^{(\mathbf{1 5})}$.

Alpha-tocopherol or vitamin $\mathrm{E}$ is the most important natural antioxidant working at the membrane level which is the first defensive line against free radicals-induced lipid peroxidation ${ }^{(\mathbf{1 6})}$. Dietary vitamin E has a marked effect in delaying atherosclerotic progression in hyperlipidemic persons, hence its protective role against many degenerative diseases ${ }^{(\mathbf{1 7}, 18)}$. Zinc, as a constituent of the antioxidant superoxide dismutase (SOD), is essential for maintenance of vitamin $\mathrm{E}$ in the blood by helping its absorption which augments tissue repair and wound healing ${ }^{(\mathbf{1 9 , 2 0 , 2 1 )} .}$ Glutathione and ascorbic acid can regenerate vitamin $\mathrm{E}$ in the liver after its oxidation ${ }^{(22)}$.
Dimethyl diphenyl bicarboxylate (DDB), extracted from seeds of Schisandra chinesis endemite, is beneficial antioxidant used in the treatment of many diseases of CVS, CNS, diabetes mellitus, neoplasms and liver especially viral hepatitis $^{(23,24)}$. It had been suggested to use DDB with other herbs to increase the therapeutic effects and prevent relapse ${ }^{(25)}$. DDB enhances the hepatic mitochondrial glutathione redox status and mitochondrial glutathione reductase (mtGRD) and has a siginificant ability to suppress the hepatotoxic increase of ALT and $\mathrm{AST}^{(23)}$. DDB also inhibits hepatotoxic lipid peroxidation and decreases carbon monoxide production and cofactor (NADPH\&O2) utilization in the liver microsomes $^{(\mathbf{2 6})}$.

The aim of the present study is to investigate the antioxidant protective capability of vitamin E and/or DDB with or without the chelator DMSA on arsenic-induced hepatotoxicity with regard of histochemical, histopathological, physiological and biochemical parameters.

\section{MATERIAL \& METHODS}

Fifty four adult male SpragueDawley albino rats weighing 170-200 gram were bred at the animal house of physiology Department, Faculty of Medicine, Tanta University and histology Department, faculty of medicine, El-Minya University. Egypt. Rats were fed with standard lab chow and water ad libitum for two weeks of acclimatization, and then randomly divided into nine groups of 6 rats each. Group I rats; were the control ones and received only 
intraperitoneal injection of $2 \mathrm{ml}$. of normal saline 2 times per week for two weeks. Group II rats; were injected with sodium arsenite in normal saline at a dose of $80 \mathrm{umol} / \mathrm{kg}$ body weight 2 times/week for 2 weeks ${ }^{(27)}$. Group III rats; were injected with the same aforementioned dose of sodium arsenite and received DMSA orally through gavages at a daily dose of $50 \mathrm{mg} / \mathrm{kg}$ body weight ${ }^{(28,29)}$. Group IV rats; were injected the same aforementioned dose of sodium arsenite and received vitamin E (alpha -tocopherol) orally at a daily dose of $100 \mathrm{mg} / \mathrm{kg}$ body weight for 2 weeks ${ }^{(30)}$. Group V rats; were injected the same aforementioned dose of sodium arsenite and received DDB orally at a daily dose of $150 \mathrm{mg} / \mathrm{kg}$ body weight for 2 weeks ${ }^{(31)}$. Group VI rats; received the same aforementioned doses of sodium arsenite, vitamin $\mathrm{E}$ and $\mathrm{DDB}$ for 2 weeks. Group VII rats; received the same aforementioned doses of sodium arsenite, DMSA and vitamin E for 2 weeks. Group VIII rats; received the same aforementioned doses of sodium arsenite, DMSA and DDB for 2 weeks. Group IX rats; received the same aforementioned doses of sodium arsenite, DMSA, vitamin E and DDB for 2 weeks. Alpha-tocopherol (vitamin E) has been obtained from EIPICO Pharmaceutical Company at Cairo.

On the fifteenth day of the experiment, animals were anesthetized by ether inhalation then blood was collected by cardiac puncture before the animals being sacrificed. Liver biopsies were fixed in $10 \%$ buffered formal saline, dehydrated in ascending grades of ethanol, cleared in xylene, infiltrated and embedded in paraplast paraffin wax. Blocks were cut into 5 um thick sections, stained with Harris' Hematoxylin \& Eosin, histochemical Periodic Acid Schiff (PAS) and finally photographed with an Olympus microscope digital camera ${ }^{(32,33,34,35)}$.

Liver tissue was homogenized and processed to determine reduced glutathione (GSH) according to the method of Griffith ${ }^{(36)}$. Glutathione peroxidase (GPx) was measured by using a commercial kit of Randox according to the method of Paglia and Valentine ${ }^{(37)}$. Malondialdehyde (MDA), an end-product of lipid peroxidation that reacts with thiobarbituric acid to yield a pinkcolored trimethine complex, was measured in liver tissue homogenate $\mathrm{(38,39,40)}^{(\text {Serum alanine }}$ amino-transferase (ALT) and aspartate amino-transferase (AST) were measured by spectrophotometric assay $^{(41)}$. All physiological measures and assays were hold at the Department of Physiology, Tanta University, Egypt.

The statistical data was analyzed for the mean and standard error by Student's $\boldsymbol{t}$-test using Microsoft Excel and Instat-3 programs. Significance was set at $\boldsymbol{P}<0.05$ level.

\section{RESULTS}

Serum ALT and AST levels and tissue MDA level showed a significant increase among the arsenic-exposed group II animals when compared to the control group I animals as shown in the Table $(p<0.001)$ indicated hepatotoxicity (ALT,AST) and oxidative stress (MDA). Administration of DMSA, alpha-tocopherol (vitamin E) and 
DDB or their combination to arsenicexposed animals ( groups III to IX) showed a significant decrease in ALT, AST and MDA of all these groups when compared to arsenic-exposed group II animals, except for the level of MDA among the rats of group IV which received vitamin $\mathrm{E}$ alone. However, this detected significant decrease did not reach the control levels (Fig. 1A, 1B).

Tissue GSH and GPx levels showed a significant decrease among the arsenic-exposed group II rats when compared to rats of the control group I $(p<0.01)$. No significant change was noted in GSH or GPx in group III rats which received arsenite and DMSA when compared to group II arsenic-exposed animals. Arsenicexposed animals treated with vitamin $\mathrm{E}$ and/or their combination with or without DMSA (groups IV to IX) showed significant increase in GSH an GPx - which approached the control level - when compared to arsenic-exposed group II rats. The later significant change indicated the ability of vitamin E and DDB to prevent the arsenic-induced depletion of GSH and GPx levels when compared with the action of the chelating agent DMSA (Fig. 1C).

Histopathological \& Histochemical Results:

The control group I showed a normal hepatic stroma and parenchyma where the radial-arranged hepatocytes appeared normal with rounded nuclei and normally dense cytoplasm while the central vein, hepatic blood sinusoids and portal tract showed normal distribution and regular continuous endothelium (Fig 2A, 2B). Glycogen or polysaccharides content of the control group I appeared normally high with the histochemical PAS-reaction (Fig. 3). The arsenic group II showed centrilobular necrosis around the central veins with many vacuolatednecrotic hepatocytes with fatty infiltration, cell lyses, indistinct boundaries, pyknotic nuclei and some other nuclei appeared fragmented (karyorrhexis) or even karyolysed (Fig.4). Perilobular (periportal) hepatocytes tended to appear slightly flattened with decreased granulation and density of the cytoplasm while some hepatocytes showed cytomegaly and karyomegaly. The damage around the portal tract (periportal or perilobular) was less prominent than that in the centrilobular area. The blood sinusoids appeared dilated and some of the lining endothelial cells showed irregularity and necrosis while other areas showed focal infiltration with inflammatory cells. Hepatocytes manifested a very weak PAS-reaction (pale pink) especially at the centrilobular necrotic areas (Fig.5).

On giving DMSA to the arsenictreated animals (group III) yielded a less centrilobular necrosis with fewer incidences of vacuolations and less frequent figures of nuclear pyknosis and karyolysis. Hepatocytes of the perilobular areas expressed mild improvement while the blood sinusoids and portal blood vessels showed mild congestion (Fig. 6). The centrilobular areas showed a weak PAS-reaction while the periportal areas explored mild to moderate PASreaction (Fig.7).

The treatment of the arsenicintoxicated animals with alphatocopherol (vitamin E) i.e. group IV 
showed hepatocytes of the centrilobular areas with more or less similar amount of vacuolations when compared to the arsenic group II, while the perilobular areas showed mild improvement of the affected hepatocytes (Fig. 8). PAS-reaction was very weak at the centrilobular areas but it was moderate at the perilobular or periportal areas (Fig. 9).

The arsenic-treated animals when given DDB (group V) showed hepatocytes of the centrilobular areas with low amount of vacuolations and lower incidence of nuclear pyknosis and karyolysis while the perilobular areas appeared with mild improvement of the affected hepatocytes (Fig.10). The centrilobular areas showed a weak PAS-reaction while this reaction was mild to moderate at the perilobular areas (Fig. 11).

The administration of both vitamin $\mathrm{E}$ and DDB to the arsenicintoxicated animals (group VI) showed hepatocytes of the centrilobular areas with less vacuolations and less figures of nuclear pyknosis, karyorrhexis and karyolysis while the perilobular areas expressed moderate improvement of the affected hepatocytes (Fig. 12). PAS-reaction was weak among the centrilobular areas while the perilobular areas showed mild to moderate reaction (Fig. 13).

The concomitant treatment of arsenic-intoxicated animals with DMSA and vitamin E (group VII) manifested less centrilobular necrosis with low amount of vacuolations and less figures of nuclear pyknosis, karyorrhexis and karyolysis. The perilobular areas showed moderate improvement of the affected hepatocytes with mild congestion of the blood vessels and sinusoids (Fig. 14). The centrilobular areas expressed weak PAS-reaction while the perilobular areas showed moderate reaction (Fig. 15).

The combination of DMSA and DDB treatment to the arsenicintoxicated animals (group VIII) showed a very little amount of vacuolations at the centrilobular areas with fewer figures of nuclear pyknosis, karyorrhexis and karyolysis with some degree of regeneration. The perilobular areas showed moderate improvement and regeneration of the affected hepatocytes with mild congestion of the portal blood vessels and sinusoids (Fig. 16). PAS-reaction was moderate at the centrilobular areas while the reaction was good at the perilobular areas (Fig. 17).

The concomitant treatment of the arsenic-intoxicated animals with DMSA, vitamin E and DDB (group IX) expressed a good regeneration of the centrilobular areas with very little figures of vacuoles and nuclear pyknosis while the cytoplasm showed normal density and acidophilia. The perilobular (periportal) areas explored marked regeneration with almost normal hepatic architecture with no cellular infiltration. Cytomegaly and karyomegaly figures were almost disappeared. The hepatic sinusoids appeared normal with no endothelial injury while the portal blood vessels are mildly congested (Fig. 18). The perilobular areas expressed a highly positive PAS-reaction while the centrilobular areas showed good positive PAS-reaction (Fig.19A\&B). 
Table: Effect of exposure treatment with DMSA, Vitamin E, DDB or their combination on ALT, AST, MDA, GSH and GPx of arsenic- induced hepatotoxicity of adult male albino rats.

\begin{tabular}{|l|l|l|l|l|l|}
\hline \multicolumn{1}{|c|}{ Parameter } & \multicolumn{1}{|c|}{$\begin{array}{c}\text { ALT } \\
(\mathbf{u} / \mathbf{L})\end{array}$} & $\begin{array}{c}\text { AST } \\
(\mathbf{u} / \mathbf{L})\end{array}$ & $\begin{array}{c}\text { MDA } \\
(\mathbf{m m o l} / \mathbf{1 0 0} \text { g. tissue) }\end{array}$ & $\begin{array}{c}\text { GSH } \\
(\text { umol/100 g. tissue) }\end{array}$ & $\begin{array}{c}\text { GPx } \\
(\text { unit/dL) }\end{array}$ \\
\hline I : Control & $26.1 \pm 2.3$ & $22.3 \pm 1.8$ & $138.6 \pm 6.1$ & $23.7 \pm 3.1$ & $6.9 \pm 0.6$ \\
\hline II : As (80umol/kg) & $81.3 \pm 1.9 * * *$ SI & $70.6 \pm 2.3 * * *$ SI & $310.5 \pm 21.2 * * *$ SI & $11.5 \pm 1.2 * *$ SI & $3.7 \pm 0.5 * *$ SI \\
\hline III: As + DMSA & $39.2 \pm 2.4 * *$ SII & $44.3 \pm 3.1 *$ SII & $219.9 \pm 10 *$ SII & $12.1 \pm 1.7$ & $3.9 \pm 0.4$ \\
\hline IV: $:$ As + Vit. E & $49.5 \pm 4.1 * * *$ SII & $49.1 \pm 3.9 *$ SII & $299.7 \pm 18.6$ & $20.7 \pm 4.1 * *$ SII & $6.1 \pm 0.7 * * *$ SII \\
\hline V: As + DDB & $53.3 \pm 3.5 *$ SII & $52.4 \pm 3.8 *$ SII & $225 \pm 17.1 *$ SII & $18.9 \pm 3.2 * *$ SII & $5.9 \pm 1.3 * * *$ SII \\
\hline VI: As+Vit.E+DDB & $47.9 \pm 3.2 * *$ SII & $46.2 \pm 3.3 *$ SII & $191.8 \pm 11.3 * *$ SII & $21.4 \pm 3.9 *$ SII & $6.5 \pm 1.6 *$ SII \\
\hline VII: As+DMSA+Vit.E & $36.6 \pm 2.4 * *$ SII & $37.4 \pm 3.2 *$ SII & $210.2 \pm 18.9 * * *$ SII & $19.2 \pm 0.8 * *$ SII & $5.9 \pm 1.4 * *$ SII \\
\hline VIII: As+DMSA+DDB & $38.1 \pm 2.2 * * *$ SII & $40.1 \pm 2.8 * *$ SII & $179.2 \pm 12.3 *$ SII & $19.1 \pm 4.5 * * *$ SII & $5.8 \pm 0.3 *$ SII \\
\hline IX: As+DMSA+E+DDB & $33.4 \pm 1.9 * *$ SII & $30.7 \pm 2.7 * *$ SII & $162.3 \pm 16 * *$ SII $/$ SI & $21.1 \pm 2.7 * *$ SII & $6.4 \pm 1.9 * * *$ SII \\
\hline
\end{tabular}

\# Results are expressed as mean \pm S.E.

$\# n=$ number of animals of each group $=6$

\# As = Arsenic or Arsenite

$\#$ ALT = Alanine Aminotransferase

$*=p<0.05$

$* *=p<0.01$

$\#$ AST = Aspartate Aminotransferase

$* * *=p<0.001$

SI = significant versus control group I

\# MDA = Malondialdehyde

\# GSH = reduced Glutathione

\# GPx = Glutathione peroxidase

\# DDB= Dimethyl diphenyl bicarboxylate

\# DMSA = Meso 2,3-dimercaptosuccinic acid 


\section{ALT $\square$ AST}

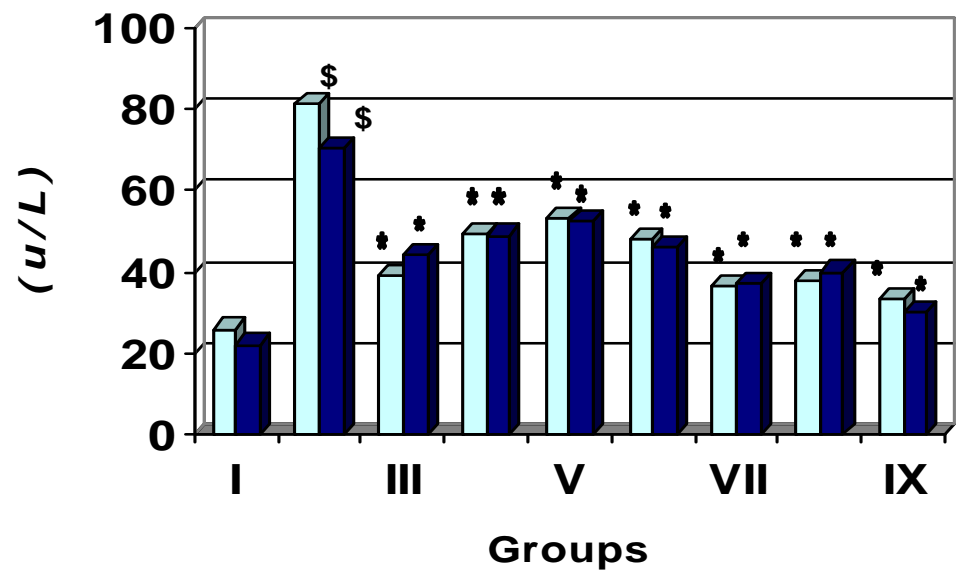

Fig. (1A): Histogram of the studied groups (I to IX) as regard serum ALT and AST. $\$$ = significant versus group I. * = significant versus group II.

\section{MDA}

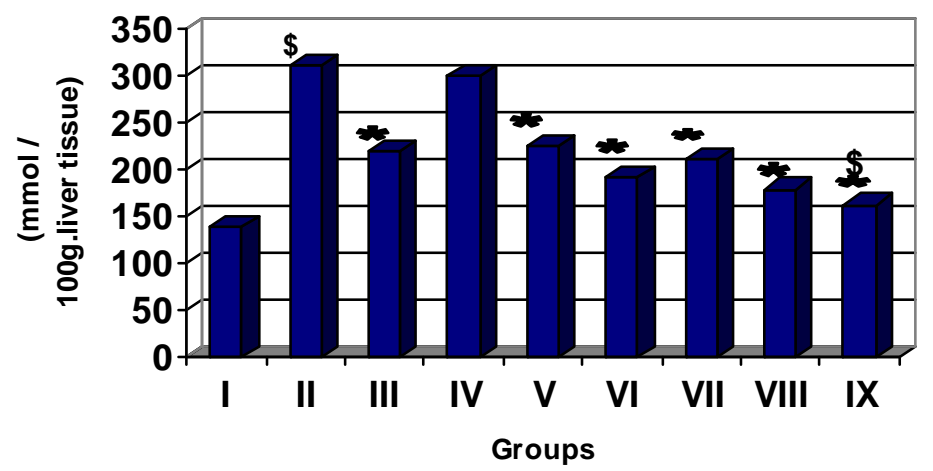

Fig. (1B): Histogram of the studied groups (I to IX) as regard tissue MDA. \$ = significant versus group I. * = significant versus group II. 


\section{$\square$ GSH $\square$ GPx}

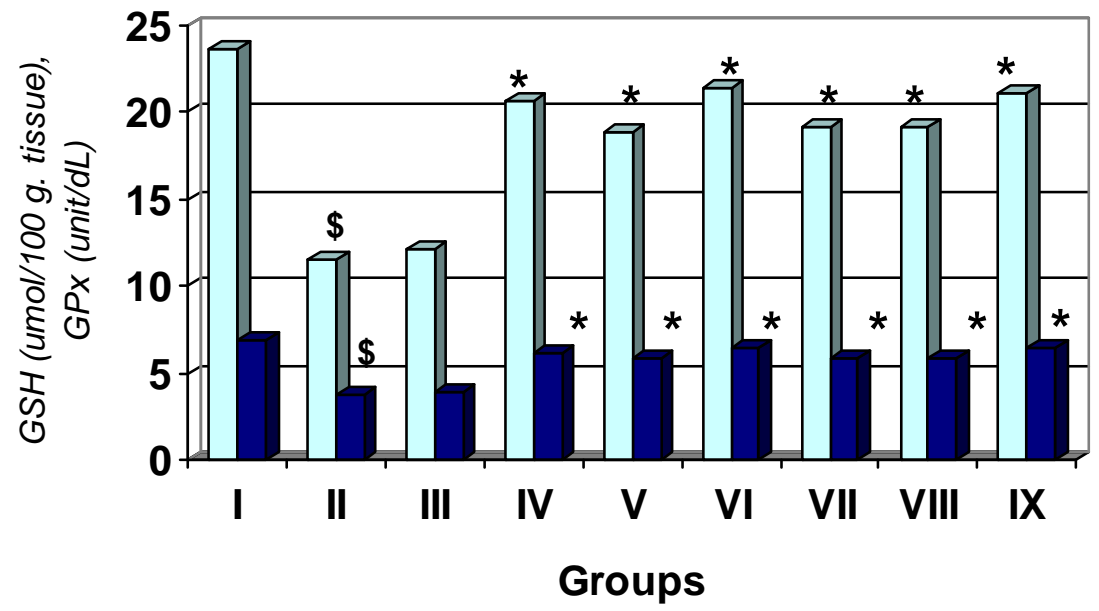

Fig. (1C): Histogram of the studied groups (I to IX) as regard tissue GSH and GPX. \$ = significant versus group I. * = significant versus group II.

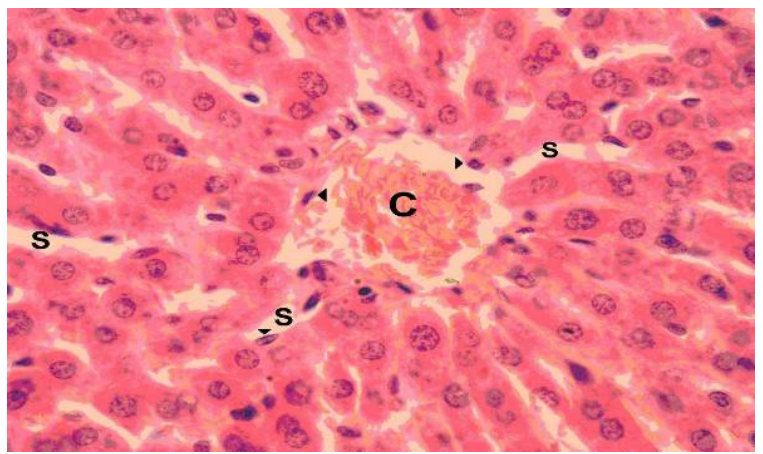

Fig. (2A): Photomicrograph of a section in the liver of control animal. Normal hepatocytes around both central vein $(C)$ and sinusoids $(S)$ with intact regular endothelium (arrowhead). (x400, Hx.\&E.). 


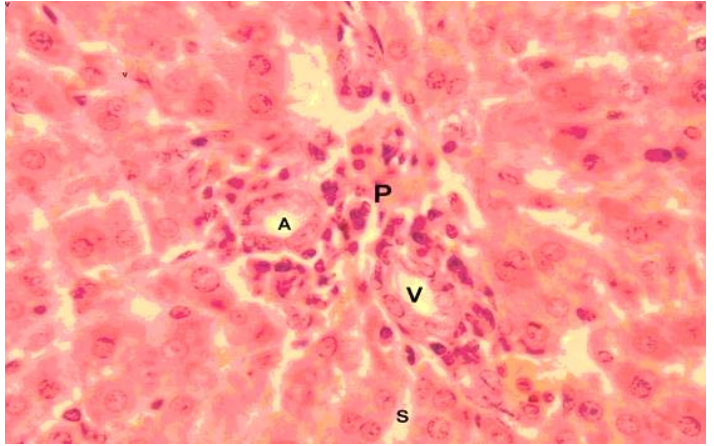

Fig.(2B): Photomicrograph of a section in the liver of control animal. Normal hepatocytes around sinusoids $(S)$ and portal tract $(P)$ vessels $(V$; portal vein and $A$; hepatic artery) with intact regular endothelium. (x400, Hx.\&E.).

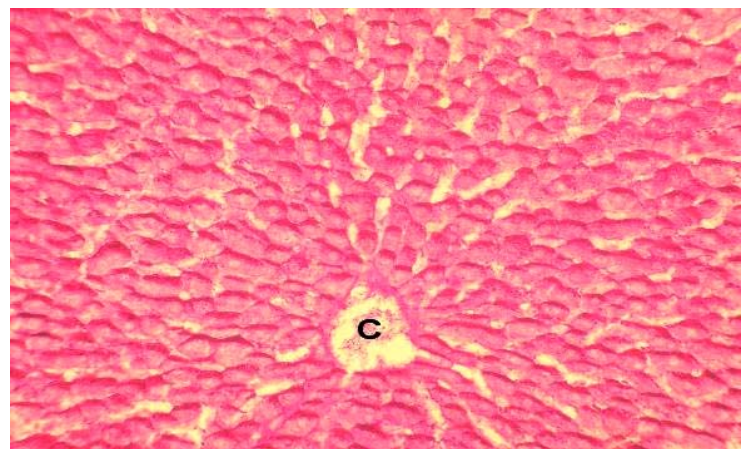

Fig. (3): Photomicrograph of a section in the liver of control animal. Normal hepatocytes granulation and density with highly positive PAS-reaction (x400, PAS).

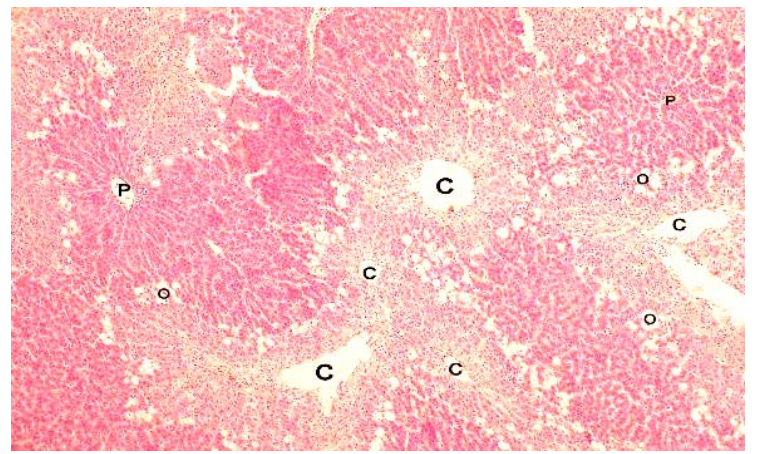

Fig. (4A): Photomicrograph of a section in the liver of an arsenic-treated animal. Centrilobular necrosis with vacuolated $(O)$ hepatocytes around central veins $(C)$ while the periportal $(P)$ areas are less affected $(x 200, H x \& E$.) 


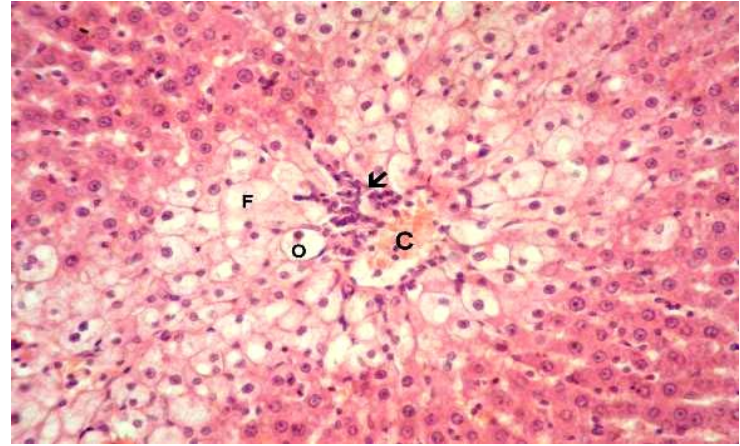

Fig. (4B): Photomicrograph of a section in the liver of an arsenic-treated animal. Centrilobular necrosis with vacuolated $(O)$ hepatocytes with fatty infiltration $(F)$. Note the inflammatory cell infiltration (arrow) around the central $(C)$ vein $(x 400$, Hx \& E.).

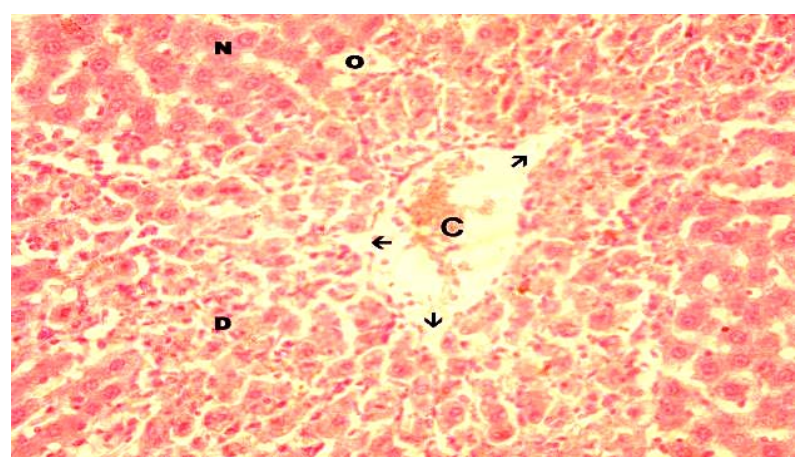

Fig. (4C): Photomicrograph of a section in the liver of an arsenic-treated animal. Centrilobular necrosis with vacuolated hepatocytes $(O)$ and abnormal acidophilia (D) due to increased binding capacity of the denaturized proteins to Eosin in contrast to the acidophilia of normal hepatocytes $(N)$. Some endothelial cells lining the central vein $(C)$ appeared injured, irregular and discontinuous. $\quad(x 400, \mathrm{Hx} \&$ E.).
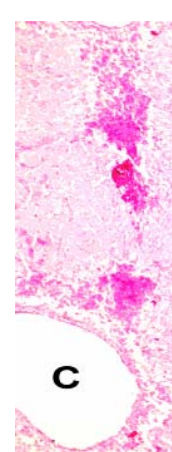
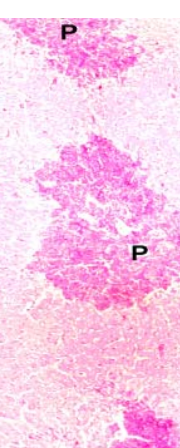

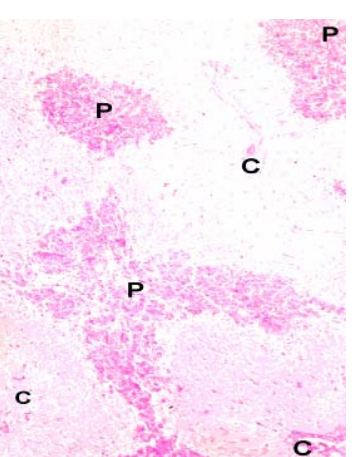

c.

Fig. (5): Photomicrograph of a section in the liver of an arsenic-treated animal. Faint hepatocytes granulation and density with very weak PAS-reaction especially at the centrilobular areas $(C)$ in contrast to the mild PAS-reaction at the periportal areas (P). (x200, PAS). 


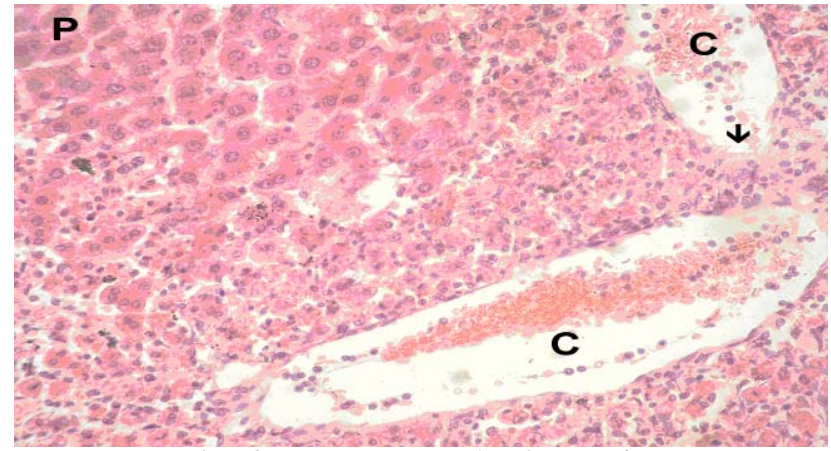

Fig. (6): Photomicrograph of a section in the liver of an arsenic-treated animal given DMSA. Centrilobular necrosis appeared with less vacuolated hepatocytes and fatty infiltration. Some endothelial cells are irregular and discontinuous (arrow). Note the nearly normal acidophilia around the periportal area $(P)$ in contrast to the abnormal one around the central veins $(C) . \quad(x 400, H x \& E$.$) .$

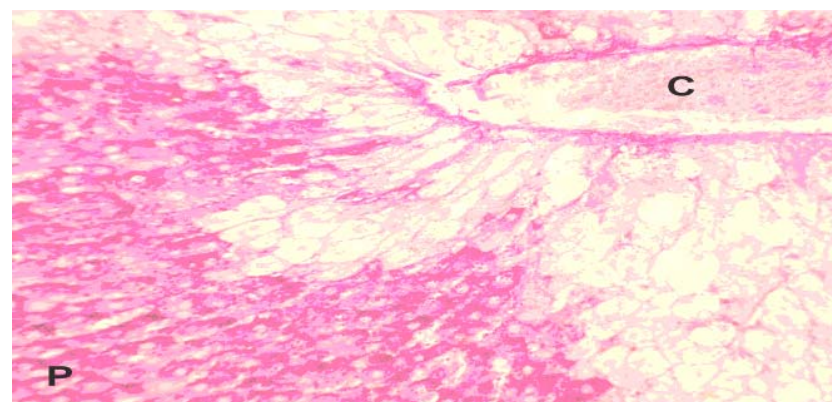

Fig. (7): Photomicrograph of a section in the liver of an arsenic-treated animal given DMSA. Centrilobular areas showed weak PAS-reaction while the reaction is moderate near the perilobular areas $(P)$. (x400, PAS).

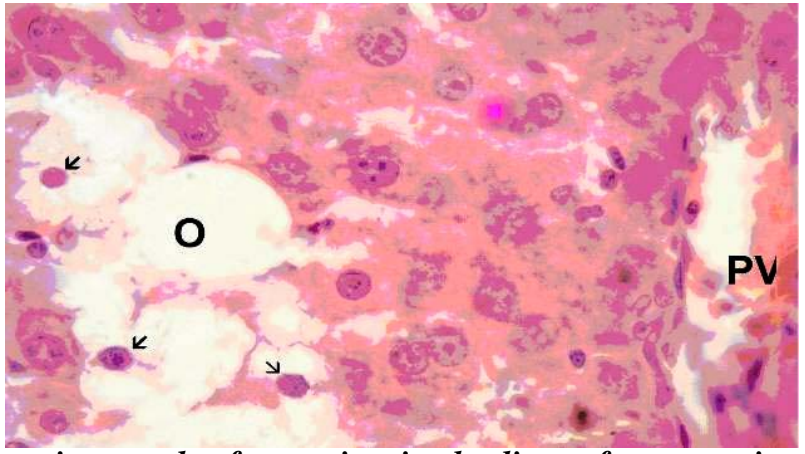

Fig. (8): Photomicrograph of a section in the liver of an arsenic-treated animal given Vit. E. Periportal area is less affected with mildly congested portal vein (PV) while vacuolated $(O)$ hepatocytes with pyknotic nuclei (arrows) are seen near the centrilobular area. (x600, $\mathrm{Hx} \& \mathrm{E}$.). 


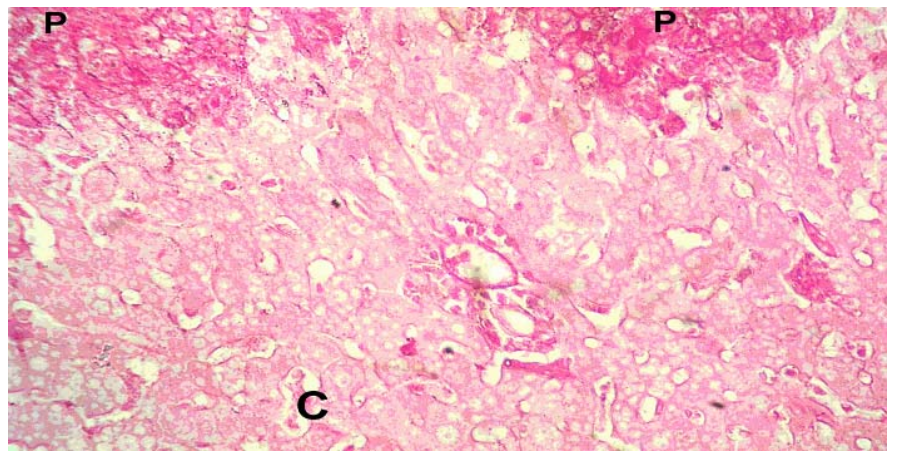

Fig. (9): Photomicrograph of a section in the liver of an arsenic-treated animal given Vit. E. Centrilobular areas $(C)$ showed weak PAS-reaction while the reaction is moderate near the perilobular areas $(P) .(x 200, P A S)$.

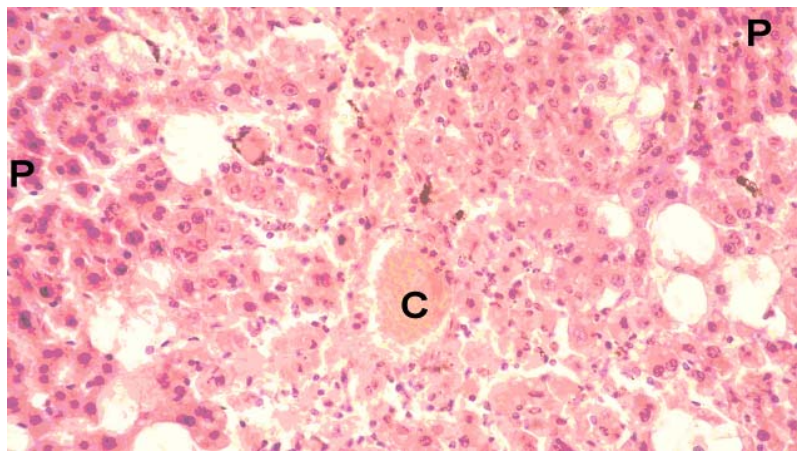

Fig. (10): Photomicrograph of a section in the liver of an arsenic-treated animal given DDB. Centrilobular necrosis with less vacuolated hepatocytes around central vein $(C)$ while the cells are less affected near the periportal $(P)$ areas $(x 250, H x \&$ E.).

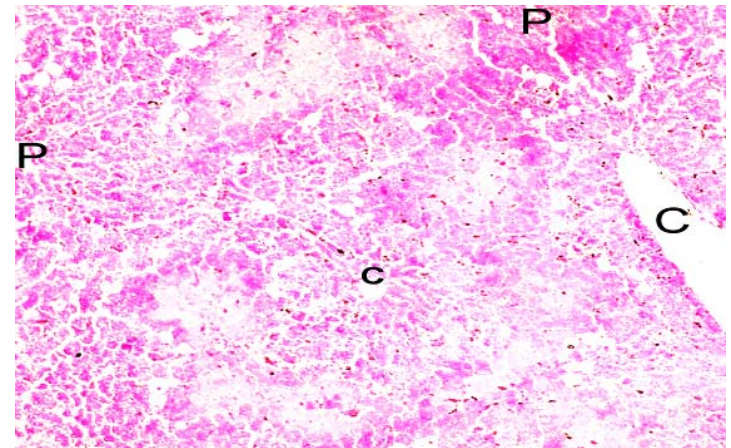

Fig. (11): Photomicrograph of a section in the liver of an arsenic-treated animal given DDB. Centrilobular areas $(C)$ showed weak PAS-reaction while the reaction is mild to moderate near the perilobular areas $(P) .(x 200, P A S)$. 


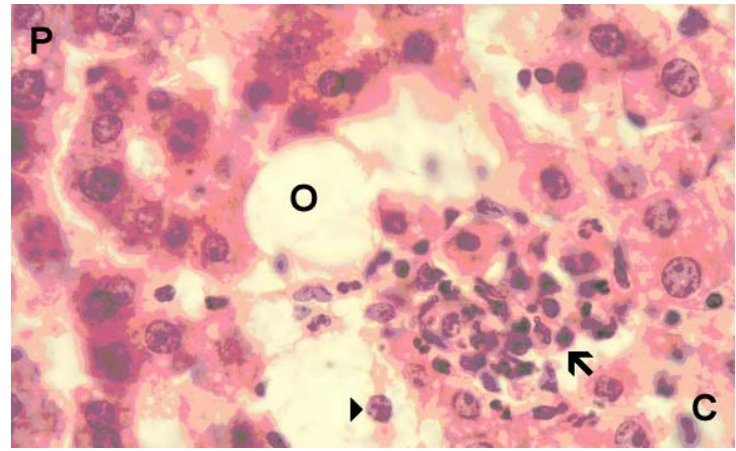

Fig.(12): Photomicrograph of a section in the liver of an arsenic-treated animal given Vit.E + DDB. Centrilobular (C) necrosis with some necrotic and vacuolated (O) hepatocytes having pyknotic nuclei (arrowhead). Focal inflammatory cell infiltration (arrow) is near the centrilobular area while the cells are less affected near the periportal areas $(P)$. (x600, $\mathrm{Hx} \& \mathrm{E}$.).

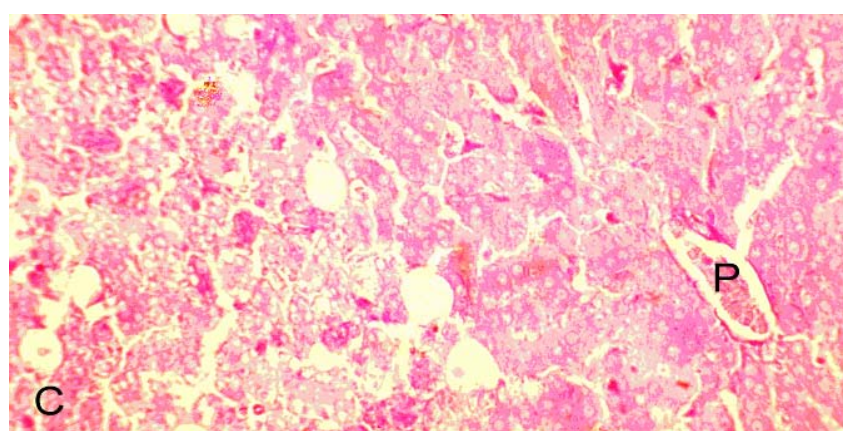

Fig. (13): Photomicrograph of a section in the liver of arsenic-treated animal given Vit. E + DDB. Centrilobular areas (C) showed weak PAS-reaction while the reaction is moderate near the perilobular areas $(\mathrm{P}) . \quad(x 200, \mathrm{PAS})$.

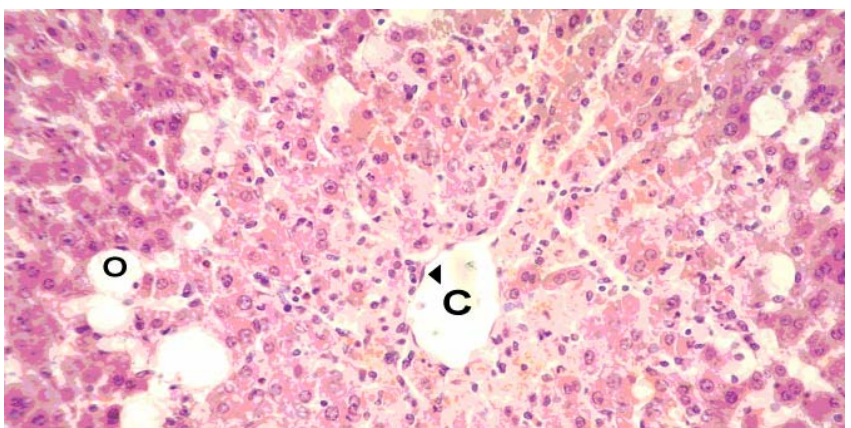

Fig. (14): Photomicrograph of a section in the liver of arsenic animal treated with $D M S A+V i t E$. Centrilobular necrosis appeared with less vacuolated (O) hepatocytes and fatty infiltration. The endothelium (arrowhead) of the central vein (C) appeared regular and continuous. ( $x 250, \mathrm{Hx} \& \mathrm{E}$.). 


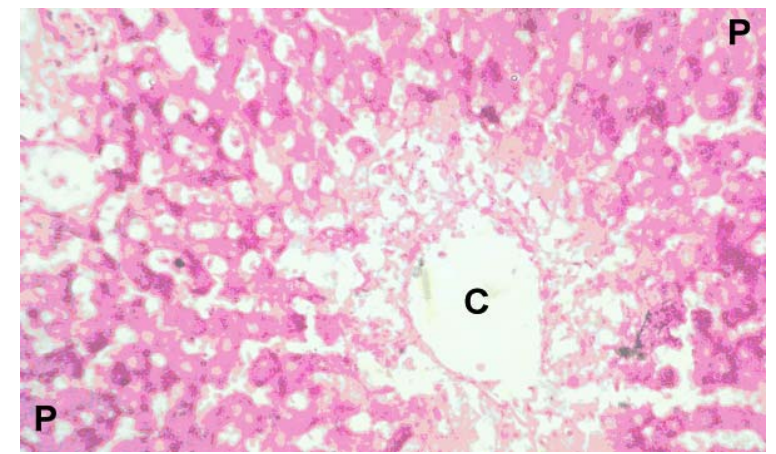

Fig. (15): Photomicrograph of a section in the liver of arsenic-treated animal given Vit. $E+D D B$. Centrilobular areas (C) showed mild PAS-reaction while the reaction is moderate near the perilobular areas $(\mathrm{P}) .(x 250, P A S)$.

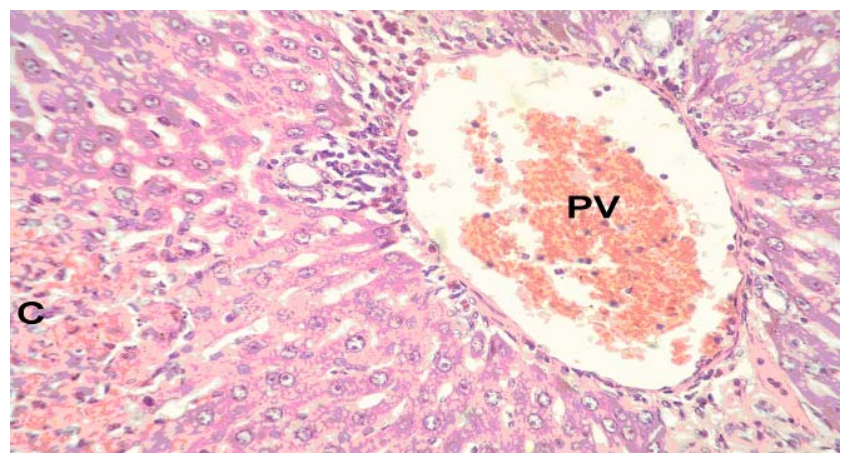

Fig. (16): Photomicrograph of a section in the liver of an arsenic-treated animal given DMSA + DDB . Perilobular hepatocytes are moderately regenerated around dilated and mildly congested portal vein (PV). The centrilobular (C) area appeared with still different acidophilia. (x250, $\mathrm{Hx} \& \mathrm{E}$.).

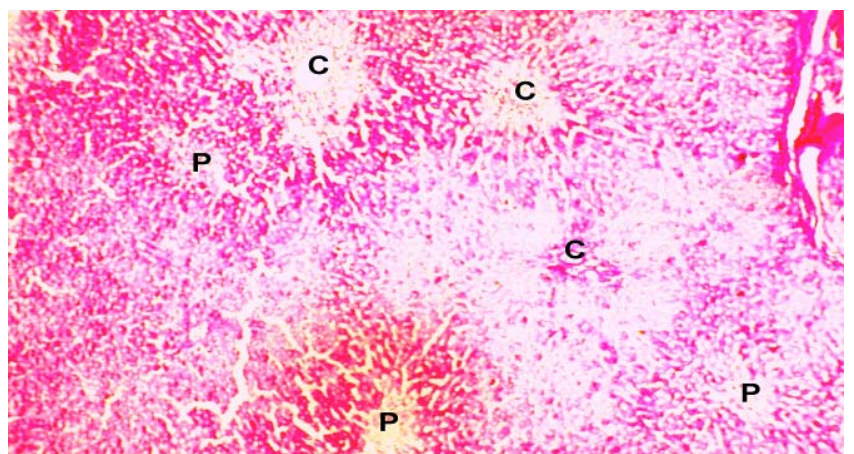

Fig. (17): Photomicrograph of a section in the liver of an arsenic-treated animal given DMSA + DDB. Centrilobular areas $(C)$ showed moderate PAS-reaction while the reaction is good at the perilobular areas $(P) . \quad(x 200, P A S)$. 


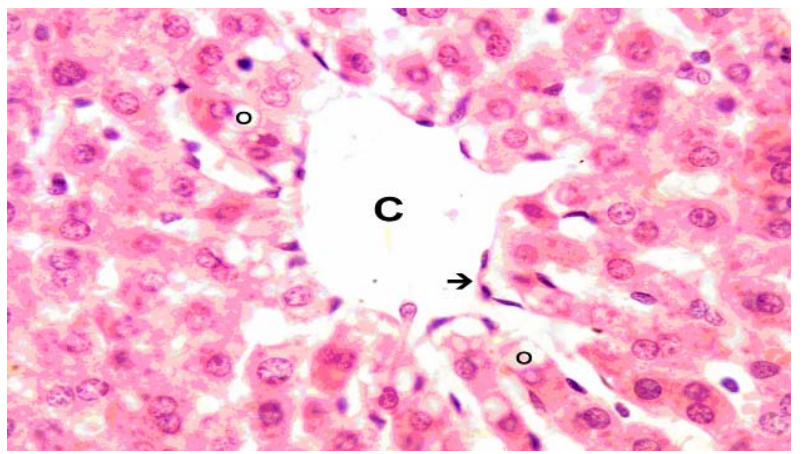

Fig. (18A): Photomicrograph of a section in the liver of an arsenic-treated animal given DMSA + Vit.E + DDB . Centrilobular areas are moderately regenerated with minimal amount of vacuolated hepatocytes $(O)$ and nearly normal acidophilia. The endothelium (arrow) appeared regular and continuous. (x500, Hx \& E.).

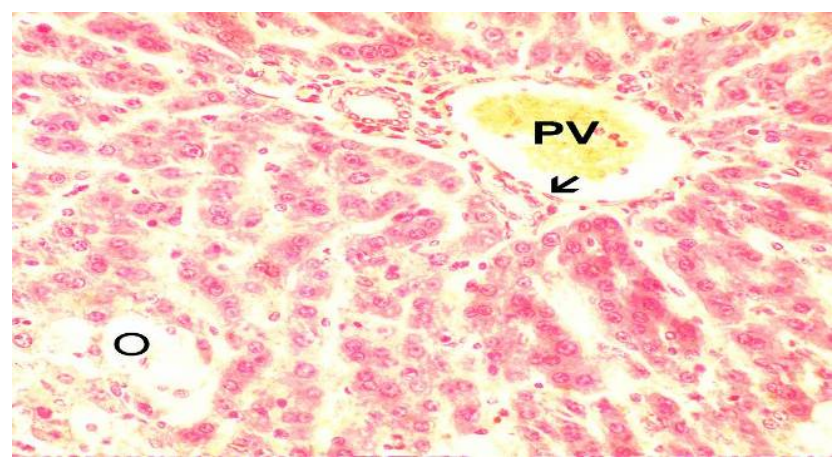

Fig. (18B): Photomicrograph of a section in the liver of an arsenic-treated animal given DMSA + Vit.E + DDB. The portal vein (PV) endothelium is regular and continuous and surrounded with well regenerated hepatocytes while minimal amount of vacuolated $(O)$ hepatocytes are seen near the centrilobular areas $(x 250$, Hx \& E.).
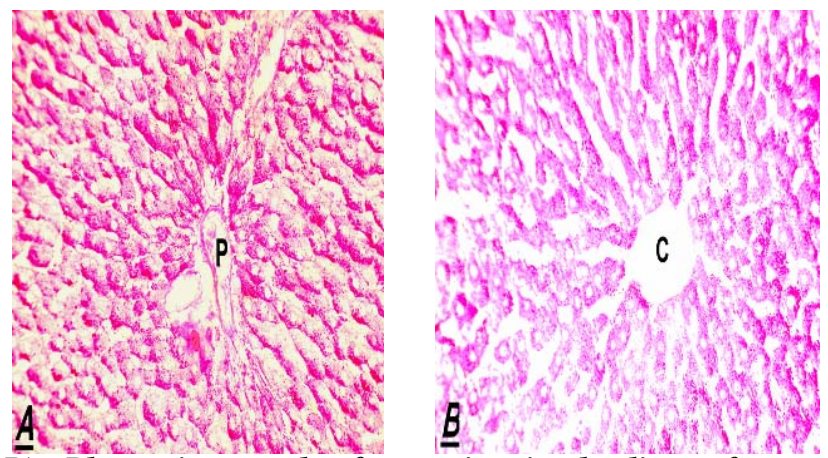

Fig. (19 A\&B): Photomicrograph of a section in the liver of an arsenic-treated animal given DMSA + Vit.E + DDB . Perilobular area $(P)$ with highly positive $P A S$-reaction while the centrilobular areas $(C)$ appeared with good positive reaction (x250, PAS). 


\section{DISCUSSION}

Arsenic, a double-edged weapon is a medicinal element and an industrial agent but unfortunately a homicidal poison and unintentional self-poison in contaminated drinking

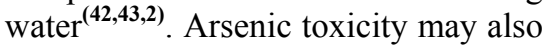
come from E-waste (electronic disposal) resulted from disposal of computers, televisions, mobile phones and other electronic devices which can leach into the soil and groundwater or may come as an airborne toxin after being incinerated $^{(44,45)}$.

Arsenic is classified as a definite -Group 1- human carcinogen with strong evidence of causation of skin, liver, lung and urinary bladder cancers ${ }^{(46,47,48,4,49,50,51,52,43,53)}$. However, the highly toxic trivalent inorganic arsenic (As III) which may contaminate the ground water, is used at an adjusted dose in the treatment of several cancers including lymphomas and acute promyelocytic leukemias by inducing apoptosis and increasing lipid peroxidation of solid tumor cells via ROS-dependant mechanism $^{(54,55,56,57)}$. Arsenic, particularly the inorganic trivalent form (As III) causes a manifested toxic effects to the parenchymal cells of many organs especially the liver, lung, skin, urinary bladder and peripheral blood vessels that may lead to the dangerous black foot disease (BFD) and gangrene ${ }^{(1,3,4)}$.

It was observed that arsenic and mercury deliver a large host of external and internal eye signs of toxicity, hence the consideration of utilizing the liver and the eye as beneficial clinical biomarkers to measure heavy metals toxicity ${ }^{(58,59)}$. Arsenic exerts its toxicity by binding to sulfhydryl groups on enzymes and other cellular proteins and also thru reactions with intracellular thiols ${ }^{(5,7,60)}$. Reduced glutathione (GSH) stimulates the methylation of inorganic arsenic to monomethyl arsonic acid (MMA) and dimethylarsinic acid (DMA) and augments excretion of the latter, hence the decreased GSH and cytochrome P450 levels in the liver and the increased lipid peroxidation with arsenic toxicity ${ }^{(8,9,61,62)}$. Arsenic toxicity is also exerted via increasing the production of ROS i.e. reactive oxygen species ${ }^{(63,64,65,57)}$. These previous studies encouraged us to utilize a delicate study design and model to specifically define the role of two promising antioxidants with or without a chelating agent against arsenic-induced hepatotoxicity with the emphasis on histophysiological, histopathological and histochemical parameters.

Arsenic toxicity whether acute, subacute or chronic produced accumulation of arsenic in the liver and kidney which lead to elevation of hepatic enzymes and histopathological changes in the form of inflammatory infiltration, steatosis and necrosis $^{(\mathbf{6 6 , 6 7 , 6 8})}$.

In the present study, reduced glutathione (GSH) and glutathione peroxidase $(\mathrm{GPx})$ were significantly depleted by arsenic administration while malondialdehyde (MDA), an end product of lipid peroxidation, was significantly elevated. This could be explained by the antioxidant effect of GSH and GPx bound to arsenic and 
detoxified it. These results are in agreement with some previous studies $^{(69,70,71,72,73)}$ who concluded that arsenic increased lipid peroxidation and protein oxidation which both represent strong indices of oxidative stress. Glutathione depletion rendered the hepatocytes highly sensitive to cell death which was manifested in arsenic group II liver tissue. Glutathione, an antioxidant against lipid peroxidation $^{(\mathbf{7 4 , 8 , 9 )}}$ is present in lower concentration at the centrilobular area in comparison with the perilobular area ${ }^{(75)}$. This rendered the centrilobular area less protected against toxins than the perilobular area which could explain the incidence of centrilobular necrosis with vacuolations, cell lyses and pyknotic, fragmented or lysed nuclei of hepatocytes. Some endothelial cells appeared slightly vacuolated, irregular with indistinct cell boundaries which could explain the dilation occurred in the blood sinusoids. This comes in accordance with some previous studies $^{(71,67,64)}$.

This endothelial injury explains the complication that may come out of arsenic toxicity-especially the chronic form-causing the peripheral vascular black foot disease (BDF) which usually ends by gangrene ${ }^{(3,4)}$. Centrilobular hepatocytes and to a lesser extent perilobular ones showed vacuolations and fatty infiltration which appeared similar to steatosis. This comes in harmony with some previous study ${ }^{(66)}$. Steatosis is a common cellular response to toxic insult and is normally reversible while its prevelance in the liver is particularly common as this organ has a major role in lipid
metabolism $^{(76,77,78)}$.

The present study showed the arsenic-intoxicated hepatocytes with lightly stained cytoplasm, less density, decreased granulations and histochemically low glycogen content explored by Hematoxylin \& Eosin stain and PAS-reaction. This could be explained by loss of ribosomes from rough endoplasmic reticulum (RER) and swelling of mitochondria with loss of their cristae as the high metabolic activity and rapid membrane transport of mitochondria may expose them as a target to heavy

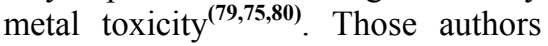
concluded that the upset in the structure and inhibition of enzymes in mitochondria might reduce their capacity to provide energy for active transport in the liver and kidney exposed to arsenic toxicity.

The observed focal inflammatory cell infiltration especially in the centrilobular areas comes in agreement with some other studies $^{\mathbf{6 7}, 68,81)}$. Cytomegaly and karyomegaly seen among some arsenic-intoxicated hepatocytes could be explained by necrotic vacuolations that expand the cytoplasm. However, karyomegaly may be explained by perturbations in DNA synthesis accompanying chemical or toxicinduced cellular proliferation. Furthermore, arsenic reduces DNA methylation and inhibits hepatic enzymes including glutathione reductase, thioredoxin reductase and methyl transferase responsible for its methylation, which may be an important contributor to carcinogenesis $^{(\mathbf{8 2 , 8 3 , 8 4 )} \text {. }}$. 
It was observed in the present study that arsenic-induced hepatocyte necrosis lead to release of liver enzymes into the blood stream which could be considered the main cause explaining the significant elevation of serum levels of ALT and AST. This comes in accordance with many

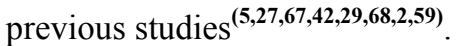

The administration of DMSA to arsenic-intoxicated animals expressed less necrotic parameters among the centrilobular areas with weak PASreaction while the perilobular areas showed mild improvement of the affected hepatocytes with mild to moderate PAS-reaction. This group explored a significant decrease of the arsenic-induced elevations of ALT, AST and MDA which could be explained due to the seldom chelating action of the administered DMSA. However, DMSA did not show any significant effect on the depleted levels of GSH and GPx concluding that DMSA has no any antioxidant role against the produced ROS on arsenic exposure. The decreased level of MDA after the administration of DMSA to the arsenic animals does not reflect any antioxidant effect as long as there is no any significant effect of DMSA on the depleted levels of GSH and GPx. This confirms the role of chelators in lowering the toxic effects of heavy metals to the extent of being used as antidotes in such cases in spite of their lacking an antioxidant role ${ }^{(\mathbf{2 8})}$.

Alpha-tocopherol (vitamin E) is the most important natural antioxidant working at membrane level ${ }^{(\mathbf{1 6})}$. Vitamin E administration to arsenic group of animals revealed almost no effect among the centrilobular necrotic areas which explored a very weak PAS-reaction while the perilobular areas showed mild improvement of the affected hepatocytes with moderate PASreaction. This indicates the protective effect of the antioxidant vitamin $\mathrm{E}$ (on the less affected perilobular areas) rather than a regenerative effect as manifested by non improvement of the heavily affected necrotic centrilobular areas. This group of animals showed a significant decrease of ALT and AST levels and a significant increase of GSH and GPx levels which comes in agreement with some previous studies ${ }^{(14,16,15)}$. However, vitamin E did not show any significant change on the elevated level of MDA. This could be attributed to the moderate effect of vitamin $\mathrm{E}$ on preserving the antioxidants GSH and GPx to the extent of improving (i.e. decreasing) the arsenic-induced elevated levels of ALT and AST but not to the extent of full depletion of the elevated lipid peroxidation. This result is contradictory to some previous studies ${ }^{(\mathbf{8 5})}$ who postulated that vitamin $\mathrm{E}$ did not have any effect in reducing hepatic lipid peroxidation.

Combined administration of alpha-tocopherol (vitamin E) and DMSA to the arsenic group animals expressed mild improvement of the centrilobular hepatocytes with weak PAS-reaction while the perilobular areas showed moderate improvement of hepatocytes with moderate PASreaction. This treatment manifested a significant improvement of all enzymatic parameters including MDA level confirming that vitamin $\mathrm{E}$ has a moderate antioxidant effect on lipid peroxidation and this effect becomes 
almost full when combined with DMSA to the extent of improving the MDA parameter.

It has been suggested that the use of dimethyl diphenyl bicarboxylate (DDB) extracted from seeds of Schisandra chinesis endemite especially when used in combination with other herbs will increase the therapeutic antioxidant effects during the treatment of many diseases of the liver, CVS and CNS as well as

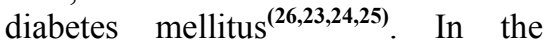
present study, DDB administration to the arsenic animals expressed mild improvement in hepatocytes of both the centrilobular and perilobular areas while PAS-reaction was weak at the centrilobular areas and moderate among the perilobular areas. This indicates the better regenerative effect of DDB in comparison with vitamin $E$ as manifested by their different effect on the centrilobular affected hepatocytes. This group showed a significant decrease of ALT, AST and MDA and a significant increase of GSH and GPx. These parameters were also significant among the arsenic animals treated with both DDB and DMSA with a particular better result as regard MDA when compared with arsenic animals received vitamin and DMSA indicating a better effective DDB than vitamin $\mathrm{E}$ in inhibiting lipid peroxidation. These results are in accordance with many previous reports $^{(\mathbf{2 6 , 8 6 , 8 7 , 8 8})}$. Ip et al. (1996) postulated that DDB may involve facilitation of both antioxidant and detoxification processes in the liver against heavy metals toxicity as indicated by the increased levels of GSH, GPx, glutathione reductase and glutathione S-transferase which confirms the role of DDB to inhibit lipid peroxidation. On the other hand, Ip et al. (2000) observed the role of DDB in decreasing the elevated levels of ALT and AST but not SDH (sorbitol dehydrogenase) induced by CCl4 intoxication, concluding that DDB had no role in the treatment of hepatic disorders. The results of the present study (14 days treatment) are contradictory to Ip et al (2000) as they analyzed the effect of a short therapy of DDB (3 days treatment) which was not enough to produce a hepatoprotective or detoxifying effect.

Hubert and Blum (2004) suggested that DDB corrected the elevated level of ALT by its effect on synthesis and/or degradation of ALT in hepatocytes by an-as yet-unknown mechanism.

The concomitant administration of vitamin E, DDB and DMSA to arsenic-intoxicated animals expressed a good regeneration of hepatocytes at the centrilobular areas with good positive PAS-reaction while the perilobular areas explored marked regeneration of hepatocytes with almost normal architecture and a highly positive PAS-reaction with normal granulation and density of the cytoplasm. This combination showed marked improvement of all enzymatic parameters with a significant decrease of ALT, AST and MDA levels and a significant increase of GSH and GPx levels. The parameters of this group showed no significant difference when compared with the control group except for MDA level which expressed a significant difference in spite of its marked depletion. This indicates that the hepatoprotective and regenerative effects of DDB and 
vitamin $\mathrm{E}$ in combination with the chelator DMSA may almost reverse and recover the hepatotoxic effects of arsenic but with considering the MDA level as a measure of the degree of lipid peroxidation improvement and recovery deficit.

The histopathological results were parallel with the histochemical and biophysiological ones as the polysaccharides or glycogen metabolism will be affected accordingly with the structural changes that affect the mitochondrial, microsomal and GERL (GolgiEndoplasmic Reticulum-Lysosomes)

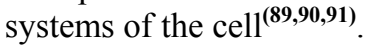

In conclusion, the data of the present study support the role of oxidative stress induced by arsenic toxicity which can be measured by the elevation of ALT, AST and MDA and the depletion of GSH and GPx levels in addition to the histopathological and histochemical degree of changes. This study explored the hepatoprotective and / or regenerative effect of two promising antioxidants (vitamin E or alpha-tocopherol and DDB) and their mutual cumulative influence against arsenic-induced hepatotoxicity especially when they are combined with a chelating agent such as DMSA. MDA level can be used as a good detector of the degree of lipid peroxidation as well as the degree of recovery deficit. Finally, the liver as regard histopathology and histochemistry is a very beneficial biomarker to measure the degree of heavy metals toxicity.

\section{REFERENCES}

1- Chen, C.L. and Wang, C.J. (1990): Ecological correlation between arsenic level in well water and age-adjusted mortality from malignant neoplasm. Cancer Res., 50: 54-70.

2- Lech, T. and Flora, F. (2005): Massive acute arsenic poisoning. Forensic Sci. Int. 151: 273.

3- Lin, M.C., Huang, Y.L., Wang, M.Y. (1998): Arsenic species in drinking water, hair, fingernails and urine of patients with black foot disease. J. Toxocol. Environ. Health A 53(2):85-93.

4- Chiu, H.F., Ho, S.C., Wang, L.Y., Wu, T.N., Yang, C.Y. (2004): Does arsenic exposure increase the risk for liver cancer? J. Toxicol. Environ. Health A. 67(19):1491-1500.

5- Aposhian, H.V. and Aposhian, M.M. (1989): Newer developments in arsenic toxicity. J. Am. Coll. Toxicol. 8: 12971305.

6- Yamanaka, K., Hasegawa, A., Sawamura, R., Okada, S. (1991): Cellular response to oxidative damage in lung induced by the administration of dimethylarsenic acid, a major metabolite of inorganic arsenic, in mice. Toxicol. Appl. Pharmacol. 108: 205-213.

7- Delnomedieu, M., Basti, M.M., Otvos, J.D., Thomas, D.J. (1993): Transfer of arsenite from glutathione to dithiols; a model of interaction. Chem. Res. Toxicol. 6: 598-602.

8- Buchet, J.P. and Lauwerys, R. (1988): Role of thiols in the invitro methylation of inorganic arsenic by rat liver cytosol. Biochem. Pharmacol. 37:31-49. 
9- Georgis, B., Cardenas, A., Buchet, J.P. Lauwerys, R. (1990): Inorganic arsenic methylation by rat tissue slices. Toxicology, 63:73-79.

10- Peel, A.E., Brice, A., Marzin, D., Erb, F. (1991): Cellular uptake and biotransformation of arsenic $\mathrm{V}$ in transformed human cell lines HeLa S3 and Hep G2. Toxic. In Vitro. 5:165-171.

11- Meister, A. and Anderson, M.E. (19983): Glutathione. Annu. Rev. Biochem. 52:711-714.

12- Burk, R.F. (1983): Glutathionedependant protection by rat liver microsomal protein against lipid peroxidation. Biochem. Biophys. Acta. 75: 7-21.

13- Asmus, K.D. (1990): Sulfer centered free radicals. Methods. Enzymol. 186:168-180.

14- Gyurasics, F., Verga, Z., Gregus, Z. (1991): Glutathionedependant biliary excretion of arsenic. Biochem. Pharmacol. 42:465-469.

15- Mezes, M., Surai, B., Salyi, G., Sbeake, B.K., Gaal, B., Maldjian, A. (1997): Nutritional metabolic diseases of poultry and disorders of the biological antioxidant defense system. Acta. Veternaria Hungarica, 45:349360 .

16- Halliwell, B. (1995): Antioxidant characterization; methodology and mechanism. Biochem. Pharmacol. 491:1341-1348.

17- Padayatty, S.J., Katz, A., Wang, Y., Eck, P., Kown, O., Levine, M. (2003): Review; Vitamin $\mathrm{C}$ as an antioxidant; Evaluation of its role in disease prevention. J. Am. Coll. Nutr. 22:18-21.

18- Salonen, R.M., Nyss, K., Porkkala-Sarataha, E., Voutilaimen, C., Rissaneen, T.H., Ristonmaa, U., Salonen, J.T. (2003): Six-year effect of combined vitamin $\mathrm{C}$ and $\mathrm{E}$ supplementation on atherosclerotic progression. Circulation 107:647-655.

19- King, J.C. (1990): Assessment of zinc status. J. Nutr. 11:14741477.

20- Bert, L.V. and Falchuk, K.H. (1993): The biochemical basis of zinc physiology. Physiol. Rev. 73:97-101.

21- Marchesini, G., Fabbri, A., Zolis, M. (1996): Zinc supplementation and amino acidnitrogen metabolism in patients with advanced cirrhosis. Hepatology, 23:1084-1087.

22- Pascoe, G.A. and Reed, D.J. (1989): Vitamin E and glutathione. Free Radic. Biol. Med. 6:209-212.

23- Ip, S.P., Yiu, H.Y., Ko, K.M. (2000): Differential effects of Schisandrin B and dimethyl diphenyl bicarboxylate (DDB) on hepatic mitochondrial glutathione redox status in carbon tetrachloride intoxicated mice. Mol. Cell Biochem. 205(12):111-114.

24- Opletal, L., Krenkova, M., Havlickova, P. (2001): Phytotherapeutic aspects of diseases of the circulatory system; Chinese magnolia (Schisandra chinesis), production of the drugs and their evaluation, therapeutic and dietary 
preparations. Ceska. Slov. Farm. 50(5):219-224.

25- Pan, S.Y., Han, Y.F., Carlier, P.R., Mak, D.H., Lam, B.Y., Ko, K.M. (2002): Schisandrin B protects against tacrine- and bis(7)-tacrine-induced hepatotoxicity and enhance cognitive function in mice. Planta Med. 68(3):217-220.

26- Liu, K.T. and Lesca, P. (1982): Inhibitory effects of Schisandra chinesis on carbon tetrachlorideinduced lipid peroxidation, metabolism and covalent binding of CCL4 to lipids. Chem. Biol. Interact. 15; 41(1):39-47.

27- Abernathy, C.O. and Obanian, E.V. (1992): Non-carcinogenic effects of inorganic arsenic. Environmental Geochemistry and Health, 14:35-41.

28- Meggs, W.J., Hoffman, R.S., Shih, Weisman, R.S., Goldfrank, L.R. (1994): Thalium poisoning from maliciously contaminated food. Clin. Toxicol. 32:723-730.

29- Tripathi, N. and Flora, S.J. (1998): Effects of some thiol chelators on enzymatic activities in blood, liver and kidneys of acute arsenic exposed mice. Biomed. Environ. Sci. 11(1):3845.

30- Patra, R.C., Swarup, D., Dwivedi, S.K. (2001): Antioxidant effects of $\alpha$ tocopherol, ascorbic acid and Lmethionine on lead-induced oxidative stress to the liver, kidney and brain in rats. Toxicol. 162:81-87.

31- Zhu, M., Yeung R.Y., Lin, K.F., Li, R.C. (2000): Improvement of phase I drug metabolism with Schisandra chinesis against CCL4 hepatotoxicity in rat model. Planta Med. 66(6): 521-525.

32- Preece, A.A. (1972): A Manual for Histological Technicians, $3^{\text {rd }}$ edition, Little Brown.

33- Drury, R.B. and Wallington, E.A. (1980): Carleton's Histological Techniques, $5^{\text {th }}$ edition, Toronto, Oxford University Press.

34- Bancroft, J.D. and Stevens, A. (1990): Theory and Practice of Histological Techniques, $2^{\text {nd }}$ edition, Churchill Livingstone.

35- Hayat, M.A. (1993): Stains and Cytochemical Methods, Plenum.

36- Griffith, O.W. (1980): Determination of glutathione and glutathione disulfide using glutathione reductase and 2-vinyl pyridine. Anal. Biochem. 106:207-210

37- Paglia, D.E. and Valentine, W.N. (1967): Studies on quantitative and qualitative characterization of erythrocyte glutathione peroxidase. J. Lab. Clin. Med. 70:158-166.

38- Buege, J.A. and Aust, S.D. (1978): Microsomal lipid peroxidation, Packer L., (ed), Methods in Enzymology, New York, Academic, 52:302-310.

39- Uchiyama, M. and Mihara, M. (1978): Determination of malondialdehyde precursor in tissues by thiobarbituric acid test. Anal. Biochem. 86:271-278.

40- Draper, H.H., Squires, E.J., Mahmoodi, H., Wu, J., Agrawal, S., Hadley, M.A. (1993): Comparative evaluation of thiobarbituric acid methods for 
the determination of malondialdehyde in biological materials. Free Rad. Biol. Med. 15:353-363.

41- Bergmeyer, H.U., Scheib, P., Wahlefeld, A.W. (1978): Optimization methods for aspartate aminotransferase and alanine aminotransferase. Clin. Chem. 24:58-73.

42- Guha Mazumder, D.N., Das Gupta, J., Santra, A., Pal, A., Ghose, A., Sarkar, S. (1998): Chronic arsenic toxicity in West Bengal; The worst calamity in the world. J. Ind. Med. Associ. 96:47, 18.

43- Yu Chen and Habibul Ahsan (2004): Cancer burden from arsenic in drinking water in Bangladesh. American Journal of Public Health, Washington. 94:741-745.

44- O'Ryan, R. and Diaz, M. (2000): Risk-Cost analysis for the regulation of airborne toxic substances in a developing contex; The case of arsenic in Chile. Environmental and Resource Economics. Dordrecht. 15: 115-120.

45- Morgan O'Rouke. (2004): Killer Computers; The growing proplem of E-waste risk management. New York. 51:12-16.

46- Basu, A., Mahata, J., Gupta, S., Giri, A.K. (2001): Genetic toxicology of a paradoxical human carcinogen, arsenic: a review. Mutat. Res. Rev. Mutat. Res. 488(2):171-194

47- Centeno, J.A., Mullick, F.G., Martinez, L., Page, N.P., Gibb, H., Longfellow, D., Thompson, C., Ladich, E.R. (2002):
Pathology related to chronic arsenic exposure. Environ. Health Perspect. 110:883-886.

48- Haschek, W.M., Rousseaux, C.G., Wallig, M.A. (2002): Handbook of Toxicologic Pathology, pp. 716-720. Academic Press.

49- Guo, H.R., Wang, N.S., Hu, H., Monson, R.R. (2004): Cell type specificity of lung cancer associated with arsenic ingestion. Cancer Epidemiol. Biomarkers Prev. 13(4):638-643.

50- Siemiatycki, J., Richardson, L., Straif, K., Latreille, B., Lakhani, R., Campell, S., Rousseau, M.C., Boffetta, P. (2004): Listing occupational carcinogens. Environ. Health Perspect. 112(15):1447-1459.

51- Tchounwon, P.B., Centeno, J.A., Patlolla, A.K. (2004): Arsenic toxicity, mutagenesis and carcinogenesis; a health risk assessment and management approach. Mol. Cell. Biochem. 255(1-2):47-55.

52- Yochida, T., Yamauchi, H., Sun, G.F. (2004): Chronic health effects in people exposed to arsenic via the drinking water; dose-response relationships in review. Toxicol. Appl. Pharmacol. 198(3):243-252.

53- Argos, M., Parvez, F., Chen, Y., Iftikhar Hussein, A.Z.M. (2007): Socio-economic status and risk for arsenic-related skin lesions in Bangladesh. American Journal of Public Health. Washington. 97:825-832.

54- Bode, A.M. and Dong, Z.G. (2002): The paradox of arsenic: molecular mechanisms of cell 
transformation and chemotherapeutic effects. Crit. Rev. Oncol. Hematol. 42(1):5-24

55- Zhu, J.B., Okumura, H., Ohtake, S., Nakamura, S., Nakao, S. (2003): The molecular mechanism of arsenic trioxideinduced apoptosis and oncosis in leukemia/lymphoma cell lines. Acta Haematol. 110(1):1-10.

56- Baumgartner, M., Sturlan, S., Roth, E., Wessner, B., Bachleitner-Hofmann, T. (2004): Enhancement of arsenic trioxide-mediated apoptosis using docosahexaenoic acid in arsenic trioxide-resistant solid tumor cells. Int. J. Cancer, 112(4):707712 .

57- Huang, C.S., Ke, Q.D., Costa, M., Shi, X. L. (2004): Molecular mechanisms of arsenic carcinogenesis. Mol. Cell. Biochem. 255(1-2):57-66.

58- El-Sherbeeny, A.M., Odom, J.V., Della-Giustina, D.E., Smith, J.E. (2006): Eye Biomarkers. Professional Safety. 51:26-33.

59- Alward, B.F.M.A. (2007): Developing a precautionary warning for heavy metals using loons as target species. Thesis, Tufts University. 102 pages.

60- Pott, W.A., Benjamin, S.A., Yang, R.S.H. (2001): Pharmacokinetics, metabolism and carcinogenicity of arsenic. Rev. Environ. Contam. Toxicol. 169:165-214.

61- Singh, P. and Sharma, R. (1994): Effect of orpiment (As2S3) on cytochrome P-450, glutathione and lipid peroxide levels of rat liver. J. Environ. Toxicol. Oncol. 13(3):199-203.

62- Hei, T.K. and Filipic, M. (2004): Role of oxidative damage in genotoxicity of arsenic. Free Radic. Biol. Med. 37(5):574-581.

63- Barchowsky, A., Klei, L.R., Dudek, E.J., Swartz, H.M., James, P.E. (1999): Stimulation of reactive oxygen, but not reactive nitrogen species, in vascular endothelial cells exposed to low levels of arsenite. Free Radic. Biol. Med. 27(1112):1405-1412.

64- Chaudhuri, A.N., Basu, S., Cattopadhyay, S., Das Guptas (1999): Effect of high arsenic content in drinking water on rat brain. Indian J. Biochem. Biophys. 36(1):51-54.

65- An, Y., Gao, Z.L., Wang, Z.W., Yang, S.H., Liang, J.F., Feng, Y., Kato, K., Nakano, M., Okada, S., Yamanaka, K. (2004): Immunohistochemical analysis of oxidative DNA damage in arsenic-related human skin samples from arseniccontaminated area of China. Cancer Lett. 214(1):11-18

66- Goyer, R.A. (1991): Toxic effects of metals. In Casarett and Doll's Toxicology, the basic science of poisons, Amdur, M.O., Doull \& C.D. Klaassen (eds.). Pergamon Press, pp. 623-680.

67- Flora, S.J., Pant, S.C., Malhotra, P.R., Kannan, G.M. (1997): Biochemical and histopathological changes in arsenic-intoxicated rats. Alcohol. 14(6):563-568.

68- Liu, J., Liu, Y., Goyer, R.A., Achanzar, W., Waalkes, M.P. 
(2000): Metallothionein-I/II null mice are more sensitive than wild-type mice to the hepatotoxic and nephrotoxic effects of chronic oral or injected inorganic arsenicals. Toxicol.Sci. 55(2):460-467.

69- Flora, S.J., Dube, S.N., Arora, U., Kannan, G.M., Shukla, M.K., Malhotra, P.R. (1988): Therapeutic potential of meso 2,3-dimercaptosuccinic acid or 2,3-dimercaptopropane sulfonate in chronic arsenic intoxication in rats. 8(2): 111-116.

70- Mourelle, M., Favaris, L., Amezcua, J.L. (1988): Protection against thalium hepatotoxicity by silymarin. J. Appl. Toxicol. 8:351-354.

71- Chang, W.C., Wu, H.L., Shi, G.Y., Murota, S.I., Mortia, I. (1991): Cytoprotective effect of reduced glutathione in arsenicalinduced endothelial cell injury. Toxicology. 69:101-107.

72- Zaman, K., MacGill, R.S., Johnson, J.E., Ahmad, S., Pardini, R.S. (1994): An insect model for assessing oxidative stress related to arsenic toxicity. Arch. Insect Biochem. Physiol. 29(2):199-209.

73- Chouchane, S. (2001): In vitro effect of arsenical compound on glutathione-related enzymes. Chem. Res. Toxicol. 14(5):517522.

74- Bus, J.S. and Gibson, J.E. (1979): Lipid peroxidation and its role in toxicology. In Review of biochemical toxicology, 1, Hodgson, E., J.R. Bend \& R.M. Philpot (eds.). Elsevier North Holland, Inc., pp. 125-149.
75- Lu, F.C. (1991b): Toxicity of metals. In Basic Toxicology; fundamentals, target organs and risk assessment, Hemisphere Publishing Corporation, New York, pp. 293-312.

76- Hiarta, F., Viveros, O.H., Diliberto, E.J., Axelrod, J. (1978): Identification and properties of two methyl transferases in conversion of phosphatidylethanolamine to phosphatidylcholine. Proc. Of Nat. Acad. Sci., USA., 72:17181725

77- Hiarta, F. and Axelrod, J. (1980): Phospholipid methylation and biological signal transmission. Science, 209:10821090.

78- Lee, T.C. and Ho, I.C. (1994): Differential cytotoxic effects of arsenic on human and animal cells. 102 Suppl. 3:101-105.

79- Woods, J.S. and Fowler, B.A. (1986): Alteration of hepatocellular structure and function by thalium chloride;m ultrastructural, morphometric and biochemical studies. Toxicol. Appl. Pharmacol. 83:218-229.

80- Leung, Ka-ming (1998): Toxocological studies of thalium in rat with emphasis on biochemical, histopathological and ultrstructural changes. Ph.D. Thesis, Chinese University of Hong Kong, People's Republic of China.

81- Pillatzki, A.E. (2007): Hepatic element concentrations and gross and histological examinations of spring migrating lesser scaup (Aythya affinis) in upper Midwest. M.S.Thesis, South 
Dakota State University. 128 pages.

82- Shimuzu, M., Hochadel, J.F., Fulmer, B.A., Waalkes, M.P. (1998): Effect of glutathione depletion and meallothionein gene expression on arsenicinduced cytotoxicity and c-myc expression in vitro. Toxicol. Sci. 45(2):204-211.

83- Snow, E.T., Schuliga, M., Chouchane, S., Zlatopolskiy, A., Hu, Y. (2000): Sub-toxic arsenic induces a multi-component protective response against oxidative stress in human cells. $4^{\text {th }}$ International Conference on Arsenic Exposure and Health Effects.

84- Stylbo, M., Del Razo, L.M., Thomas, D. (2000): Toxic consequences of metabolism of arsenic. $\quad 4^{\text {th }} \quad$ International Conference on Arsenic Exposure and Health Effects.

85- Garg, M.C., Singh, K.P., Bansal, D. (1997): Effect of vitamin $\mathrm{C}$ supplementation on oxidative stress in experimental diabetes. Indian J. Exp. Biol. 35(3):264-266.
86- Ip, S.P., Poon, M.K., Che, C.T., Ng, K.H., Kong, Y.C., Ko, K.M. (1996): Schisandrin B protects against carbon tetrachloride toxixcity by enhancing the mitochondrial glutathione redox status in mouse liver. Free Radic. Biol. Med. 21(5):709-712.

87- Xuejiang, W, Magara, T., Konishi, T. (1999): Prevention and repair of cerebral ischemiareperfusion injury by Chinese herbal medicine, Shengmai san, in rats. Free Radic. Res. 31(5):449-455.

88- Hubert, E. and Blum, M.D. (2004): DDB treatment of patients with chronic hepatitis. Hepatology. 39(6).

89- Mathew, C.K. and Van, K.E. (1996): Biochemistry. $2^{\text {nd }}$ edition, Benjamin Publishing Company, Menlo Park, USA, pp:219-313.

90- Guyton, A.G. and Hall, J.E. (2006): Textbook of Medical Physiology, $11^{\text {th }}$ edition New York, W.B. Saunders Company. Ch.36, 60, 70.

91- Junqueira, L.C. and Carneiro, J. (2006): Basic Histology, $11^{\text {th }}$ edition, Lange Medical Books McGraw-Hill, USA. 


\section{التقييم الهستوفيزيولوجى لأثر فيتامين هاء (الألفا توكوفيرول) والحبة التئية

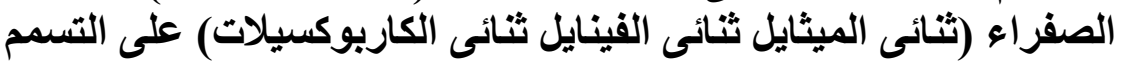

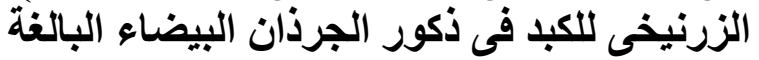

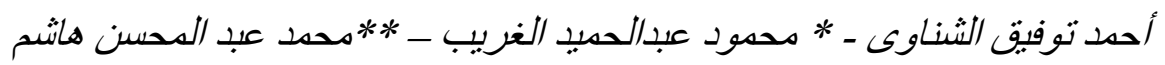

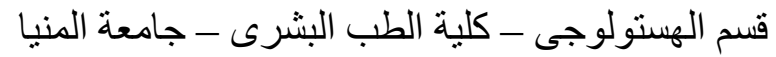

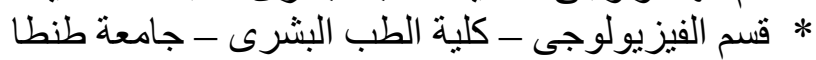

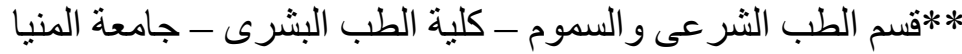

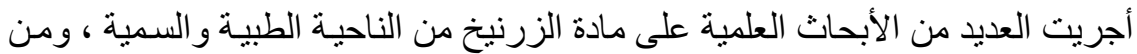

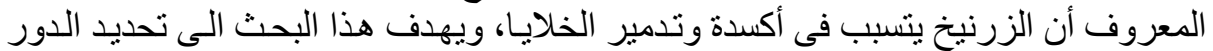

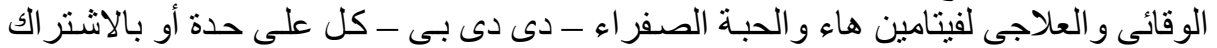

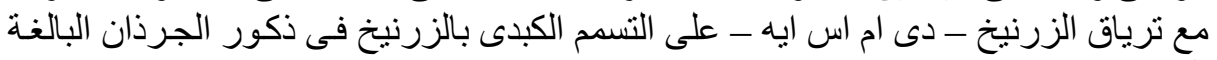

وقد أجريت هذه الدر اسة على أربعة وخمسين جرذا، تم تقسيمها الى تسع مجمو عات ، وكل مجمو عة تثمل ستة جرذان على النى النحو التالى:

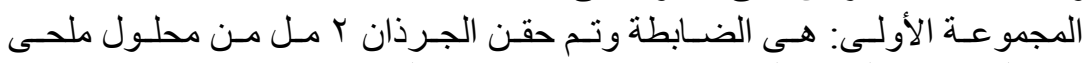

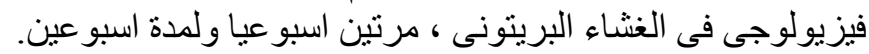

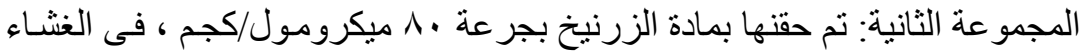

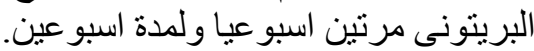

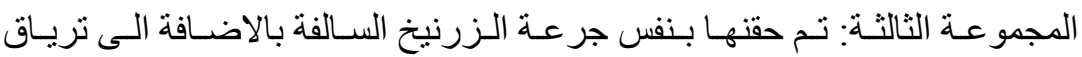

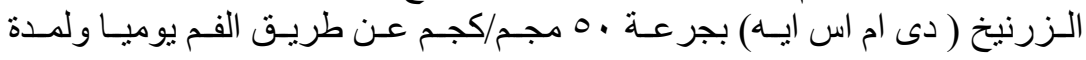
اسبو عين.

الجممو عة الر ابعة: تم حقنها بنفس جر عة الزرنيخ السالفة بالاضافة الى فيتامين هاء

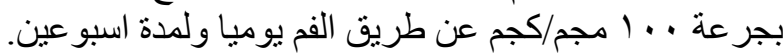

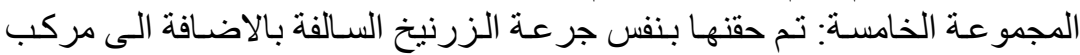

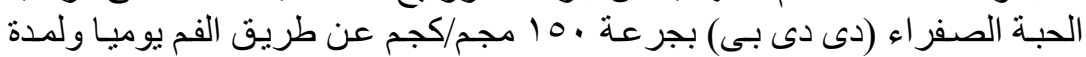

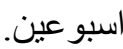
المجمو عة السادسة: تم حقنها بنفس جر عة الزرنيخ السالفة بالاضافة الى فيتامين هاء

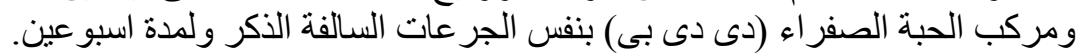

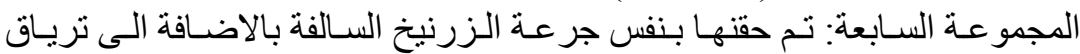
الـزرنيخ (دى ام اس ايسه) و فيتـامين هـاء بـنفس الجر عـات السـالفة الـذكر ولمـــة

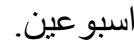

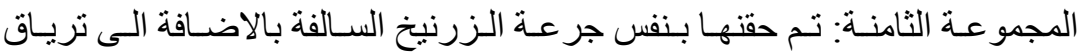

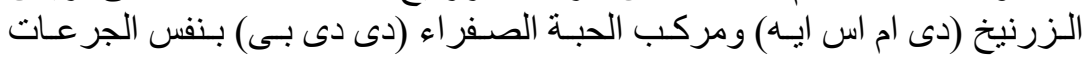

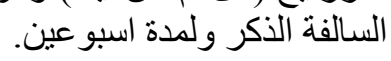


المجموعـة التاسـعة: تم حقنهـا بـنفس جر عـة الزرنيخ السـالفة بالاضــافة الـى تريـاق

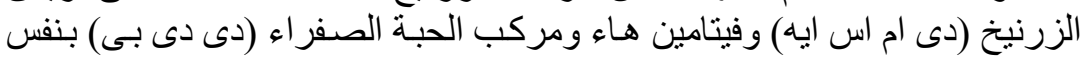
الجر عات السالفة الذكر ولمدة اسبو النيو عين.

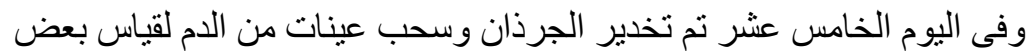

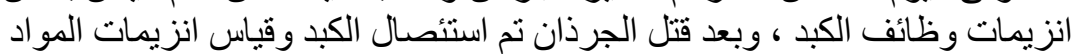

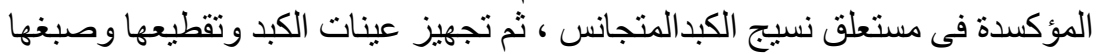
للفحص الهستو باثولوجى و الهستو كيمبائى.

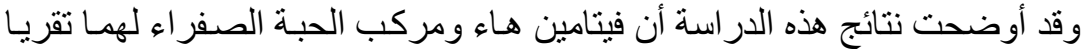

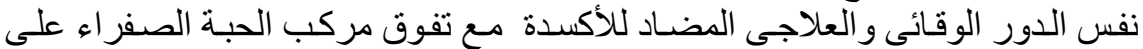

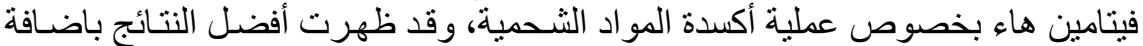
ترياق الزرنيخ (دى ام اس ايه) للعلاج بفيتامين هاء أو الحبة الصفر اء أو أو كليهما معا، مما

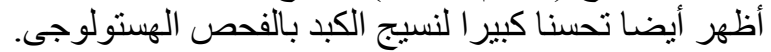

